\title{
Using computers in introductory psychology
}

\author{
PETER HORNBY and MARGARET ANDERSON \\ State University of New York College at Plattsburgh, Plattsburgh, New York
}

\begin{abstract}
This paper describes our experience during the past 2 years in establishing a computer-based laboratory for introductory psychology. Discussion includes selection of hardware; physical design of the laboratory; locating, reviewing, and selecting courseware; development of supplementary materials; operation and management of the laboratory; and integration of the laboratory into the curriculum. These factors are examined from the point of view of the decisions made, the difficulties encountered, and the lessons learned.
\end{abstract}

Laboratory instruction has traditionally been a standard component of high school and college science courses, and psychology has followed this standard. However, large enrollments, lack of space, and the high cost of equipment have begun to limit the opportunities to offer these laboratory experiences. Recently, there has been a great deal of interest in employing the microcomputer for instructional laboratories. Discussion began about 3 years ago at Plattsburgh regarding the possibility of establishing a multipurpose microcomputer laboratory for instructional purposes in the psychology department.

Coincidentally, at this time (the fall of 1985) the university announced that limited funds were to be made available on a competitive basis to academic departments to encourage the incorporation of computers into their instructional programs. The psychology department developed a proposal and received support to establish a computerized instructional laboratory in the department to support courses in learning, research methods, cognition, perception, and introductory psychology. The laboratory was expected to be used for both graduate and undergraduate research activities. These uses appeared to be consistent with the directions in which computerized instruction was moving (Castellan, 1986; Eamon, 1986; Eamon $\&$ Butler, 1985). At the present time computerized instruction is used in three courses: Cognitive Psychology, Learning and Memory, and General Psychology. The task of incorporating computers into the introductory course has been particularly difficult, largely because of difficulties in locating appropriate and useful courseware. However, we have made progress and are now able to offer a full-semester, independent laboratory course that supplements the standard course in introductory psychology.

The general psychology course, in which about 400 students enroll each semester, has not included a formal laboratory component since the early 1970s. Primary in-

This research was supported in part by a grant from the Central Awards Committee, Faculty Grants for the Improvement of Undergraduate Instruction, The Research Foundation of the State University of New York. Requests for reprints should be sent to Peter Hornby, Department of Psychology, State University of New York College at Plattsburgh, Plattsburgh, NY 12901. struction has been by large lecture format, with very little individual attention and almost no hands-on experience. The large number of students, the high cost of research equipment, and the changing focus of the discipline have made the traditional laboratory unfeasible.

\section{Hardware Selection}

The initial budget allocation of $\$ 12,000$ was used to purchase four microcomputers, appropriate peripherals, and supporting software. The question of microcomputer type was simplified because the administration supported the Apple and the Zenith systems campus-wide. A review of the available courseware literature (Academic Computing Center of Gettysburg College, 1984) indicated that the Apple systems were the most widely used and best supported. However, trends in both research and instructional computing suggested that MS-DOS compatible systems were gradually moving into their own in higher education. Also, the State University of New York has an excellent educational purchase agreement with Zenith; with a limited budget, this was an important consideration. Finally, two major distributors of psychology courseware, CONDUIT and Life Science Associates, were increasingly making their products available in MS-DOS compatible versions.

Based on the above considerations, the decision was made to purchase four Zenith 157 computers with dual disk drives, expanded memory, and color monitors. In addition, the order included one printer, an eight-color plotter, and appropriate hardware to support interfacing with existing laboratory equipment. Although this is certainly a limited facility, it provides the basics to implement the program and determine the feasibility and advisability of making a major commitment to instructional computing.

\section{Physical Structure of the Laboratory}

A newly remodeled laboratory facility that consisted of a classroom and six small private rooms was available to house the laboratory. One microcomputer was installed in each of four small rooms, a Commodore 64 with biofeedback equipment was located in the fifth room, and the sixth room was used as an office. We were not plan- 
ning a great deal of classroom instruction in computer programming, so there was no need to locate the machines in a central facility. The advantages of privacy and the ability for students to concentrate on their work outweighed the possible advantages of easy observation and close monitoring of equipment. In addition, with the limited number of machines available, it was anticipated that students would sometimes work in teams, and the separate rooms would allow conversation without interrupting other users. As the facility is expanded, the individual rooms will be maintained for student research and independent projects, but a centralized unit for instruction and laboratory classes will be established.

\section{Selection of Courseware}

Several factors influenced courseware selection. First, the primary interest was in providing laboratory demonstrations of the basic empirical phenomena to which students were exposed in the introductory course. Ideally, the students would participate in representative exercises for each of the major topical areas. Also, it was considered essential that the material not require extensive background in specific content areas so that students would not become overwhelmed and confused, but would instead gain a feeling of competence. Third, although it was expected that students would acquire a greater understanding of the relevant concepts, a more important goal was having them become involved with and excited about scientific psychology. It was also felt that the students should participate interactively in activities that result in the collection of behavioral data that they could analyze and interpret. Finally, we thought that each lesson should be self-contained and that each student should be able to work independently. These factors led to an emphasis on simulated experiments or behavioral measures in which the student would serve as subject.

Several introductory-level packages were advertised for MS-DOS compatible computers. These packages include PsychSim (Ludwig, 1986), Discovering Psychology (Levy, Grant, Morgan, \& Yunker, 1985), Simlabs (Queen's University Psychology Department, 1986), and PSYCHAID (Huffman, Vernoy, \& Williams, 1987). Although these packages were produced primarily to supplement textbooks in introductory psychology, they were also advertised as being available for purchase independently. The promotional literature described each of these packages as containing a series of programs designed to supplement instruction in the areas traditionally covered in introductory psychology. Although emphasis was on cognition and learning, other areas, including developmental, social, and clinical psychology, were represented. Simlabs, described as including eight units that each contained three independent demonstrations or experiments, was particularly impressive. In addition to the typical areas, the advertised units included physiological and pathological processes, personality, psychological testing, and motivation/emotion.
Although we were unable to locate reviews of any of these packages, we decided to order single copies of Discovering Psychology and Simlabs, feeling reasonably confident that these were the type of materials needed. However, the decision to purchase multiple copies of any courseware was postponed until we had a chance to review a copy and have some students use it. We were unable to obtain further information from the producers about PsychSim and PSYCHAID at that time, so they were not considered further for adoption.

\section{Initial Implementation}

Both the hardware and the software were ordered during the summer of 1986, and it was anticipated that the lab could be set up and testing of the materials begun by the beginning of the fall semester. Our goal was to offer some form of laboratory instruction in introductory psychology by the following spring semester. Unfortunately, we were not familiar at that time with the warnings that are now available about the difficulties of using computers for instruction (Castellan, 1986; Eamon, 1986; Vom Saal, Eckerman, Balsom, \& McDaniel, 1984). We did not anticipate the time and energy that would be required and the frustrations and problems that would be encountered. In retrospect, we probably would not have taken these warnings seriously enough, even if we had been aware of them.

Although most of the hardware and some of the software had arrived by the fall semester, the decision was made to wait until the spring before attempting to use computers in the introductory course. Actually, only three of the eight Simlabs units had arrived at that time, and, upon investigation, we learned that the other units were still under development. During the fall term, a small group of advanced students, who were serving as teaching assistants for introductory psychology, began to review the courseware. The students were simply given the individual programs and the supporting documentation as delivered and were asked to run through each program and provide evaluative feedback. Five questions were of primary interest: Were students able to successfully complete the activities? Were the directions sufficiently clear? Were the programs interesting and/or instructional? Would the material enhance the existing course? Was there enough supporting documentation?

In the spring term of 1987, introductory-level students were exposed to these materials on a very limited scale. Traditionally, one section of the introductory course is taught using a self-paced format. The design of this course seemed particularly well-suited to the incorporation of computerized activities, since students work on an individual basis under the guidance of teaching assistants. Students are required to earn a number of points from optional activities, in addition to those points obtained from quizzes and exams, so the computer exercises were simply added as options. Because this course is self-paced and has a relatively small enrollment (about 60 students 
per semester), the courseware could be made available to students without concern about the problems of multiple copies or limited availability of equipment. Students could come to the lab during the $12 \mathrm{~h}$ each week that were set aside for this course, sign out a disk for an activity of their choice, and complete the exercise at their own pace. Teaching assistants were available to show them how to use the equipment, provide background information, indicate sections of the text that were related to the demonstration, provide follow-up in the form of questions and discussion, and help them with any difficulties they encountered. They also pointed the students toward the better programs, in terms of both technical accuracy and pedagogical soundness. The introductory students were also required to write a summary of their experiences to provide more evaluative student feedback.

\section{Problems and Solutions}

Although some difficulties were expected, we were not prepared for the number of problems encountered. We had expected the programs to provide background information on the exercises, to make the learning objectives clear, and to provide questions and reviews to assure that understanding had occurred. For the most part, these basic pedagogical devices appeared to be lacking, and students were often unsure about the goals of the programs. Many students referred to the programs as "games" and frequently commented that the exercise was "fun" but that they did not understand what they were supposed to be learning. Another problem, particularly common with the Simlabs units, was that the program simply did not do what was indicated. Occasionally, the introduction indicated activities that were not available. Sometimes the programs failed to store and/or display necessary data regarding subject responses. In addition, students found that some programs accepted erroneous input that was subsequently included in the results. Several programs failed to provide any option to exit from the exercise other than to reboot the entire system. Another problem with the Simlabs materials was that the menu system was so cumbersome that many students found it difficult to use. On the brighter side, students found some of the exercises instructional and stimulating and felt that, with appropriate corrections, modifications, and the addition of supporting documentation, they could provide valuable learning experiences.

In light of these difficulties, we concluded that an intensive review was required to determine what programs could be used and what supporting material would be required. It was also decided that formal implementation of a computerized lab would be postponed until this work had been completed. During the summer of 1987, a systematic review of each program was conducted. Student evaluations were consulted, and a determination was made regarding whether the program could be used in its present form or whether modifications were needed. By this time, an additional set of programs, titled Computerized Activities in Psychology II (CAPSII) (Gorman, 1986), had been obtained. This package provided an additional 10 programs that were included in our review.

Of the 41 instructional programs in our library, we hoped to identify those that were instructionally valid and represented as broad a range of topical areas as possible. Many of the programs were not usable, but some that had only minor bugs might be salvaged through the provision of "special instructions" in the supporting documents that were being developed. This effort resulted in the identification of a set of 20 programs that were considered to be instructionally valuable. Worksheets were then developed to accompany each program. The worksheets contain a brief introduction to the concepts covered in the exercise, learning objectives for each exercise, special instructions identifying any unique characteristics of the program, and a set of questions that relate the exercise to material covered in the course or to students' personal experiences.

Programs were identified that supported 8 of the 15 chapters of the introductory psychology text (Scarr \& Vander Zanden, 1987). Materials dealing with the biological basis of behavior, adolescence and adulthood, personality theory, mental health, and methods of intervention were not included in the available packages. Several topics were identified in each of these areas as being suitable for computerized laboratory activities, and hopefully it will be possible to locate such activities in the future.

Reviewing the materials in these packages has taught us a great deal about commercial software for the introductory course. We determined some of the questions to be asked in selecting additional software. Is there a favorable, published review of the program or the package? (Very few exist.) Does the publisher provide the opportunity for preview of the package? (Occasionally only select programs, presumably the best, are provided.) Are the concepts that are demonstrated clearly related to the content and objectives of the course? (Just because a program is in a package designed for a particular course does not guarantee that it is related.) Is there sufficient background information, either as part of the program or in supporting documentation? (Too often this is completely missing.) Does the program provide clear instructions that allow the student to do the exercise without confusion? (This is particularly important at the introductory level for students who are inexperienced with computers.) Does the program provide a convenient means for the student to exit from the program, return to the main menu, or begin a section again? (Students sometimes select the wrong program or make a fundamental mistake that requires their starting over.) Is the program resistant to erroneous input, and does it provide feedback to the student to correct improper responses? (The worst situation is when a program accepts the wrong input.) Is there appropriate and attractive use of color, sound, and graphics? (Students find sound and graphics engaging and enjoyable.) Does the program provide an interactive experience that could not be just as easily accomplished using a different medium? (There is no point in having students sim- 
ply read text from the screen.) Can the program be modified or corrected if desired? (Small changes can be made locally without having to discard the entire program.) Can DOS and/or the required interpreter be installed on the program disk? (The fewer disks a student has to work with, the less chance of error.) Does the program accumulate data where appropriate and provide a summary for the student at the end of the exercise? (Without this, the student is left with no information about the experience.)

It would probably not be hard to add to this list, but these are some of the most important considerations.

\section{The Current Laboratory}

\section{Component and Future Plans}

The set of computerized exercises constitutes one component of the self-paced section of our general psychology course. Since this aspect of the course is still in the developmental stage, students are not required to complete all the exercises. Although attending the computer lab is only one of several options available in the course, it is clear by now that almost all students are selecting this option for obtaining the necessary points, and their high return rate and written feedback indicate that they are finding it enjoyable and motivating. The course syllabus contains a list of the laboratory activities available for each chapter of the text. Students who have completed a chapter can visit the lab and sign out the appropriate disk. The teaching assistant on duty provides them with a folder containing the disk, special instructions on the use of the particular software, and a copy of the worksheet for the activity they have selected. Although several chapters are supported by two or more activities, students are encouraged to complete only one activity at a time, most of which require from 15 to $20 \mathrm{~min}$ on the computer. In addition to providing a general introduction to the activity, the worksheet includes directions for recording data when appropriate and a set of questions to stimulate the students to integrate their lab experience with the course material and to relate it to their personal experiences. Students are encouraged to take the worksheets home and to work on the questions at their own pace. After completing the worksheet, a student submits it for evaluation and comment and then meets with the teaching assistant to review the entire experience. At that time, each student completes a brief evaluation form covering all aspects of the activity and the assignment. In this way, modifications and improvements of the materials will continue to be made as the programs are used.

In the spring of 1988, a one-credit laboratory course is being offered that can be taken in conjunction with the general psychology course or by students who have already completed the introductory course. The current laboratory facility can handle a total of 60 students, in five sections of 12 students each. Each section involves a 2-h lab period per week, during which time the students complete the specified computer activity. Most of the activities require less than $40 \mathrm{~min}$, and the students use the remaining time to work on the exercises in the workbook. Prior to the next lab meeting, students are expected to have completed the written assignment, and the beginning of each lab session is devoted to group discussion and review of the previous week's activity.

Offering a small number of independent laboratory sections provides a further opportunity to evaluate the laboratory experience, to determine the extent of the demand for the course, and to develop effective procedures for managing the facility. If this pilot program is successful, the facilities will be expanded and the laboratory course will become a standard part of the introductory course.

\section{Conclusions}

It has taken over 2 years for the department to feel prepared to offer a computerized laboratory course at the introductory level. During this time three major conclusions were reached. First, it must be emphasized that the decision to incorporate computerized instruction into an introductory course should not be made without full awareness of the time and effort that is going to be involved. Although the marketing materials lead one to believe that the only requirements are the hardware, the space, and the purchase of courseware, this is far from true. Second, much of the software that is currently available at the introductory level is poorly developed and inadequately documented. There appears to be room for significant improvement in this regard. Finally, despite the effort required, computerized instruction at the introductory level can provide a hands-on, interactive experience that is a feasible alternative to traditional laboratory activities. It is an alternative that students seem to find both engaging and educational.

\section{REFERENCES}

Academic Computing Center of Gettysburg College. (1984). Computing in undergraduate psychology: A practicum. Software guide. Gettysburg, PA: Author.

Castellan, N. J. (1986). Issues in the effective use of computers in introductory and advanced courses in psychology. Behavior Research Methods, Instruments, \& Computers, 18, 251-256.

EAMON, D. B. (1986). Integrating a computer component into the student psychology laboratory: Problems and prospects. Behavior Research Methods, Instruments, \& Computers, 18, 245-250.

EAMON, D. B., BUTLER, D. L. (1985). Instructional programs for psychology: A review and analysis. Behavior Research Methods, Instruments, \& Computers, 17, 345-351.

GoRman, B. S. (1986). Computerized activities in psychology II [Computer program]. New York: Random House.

Huffman, K., Vernoy, M., \& Williams, B. (1987). PSYCHAID [Computer program]. New York: Wiley.

Levy, C. M., Grant, J. L., Morgan, M. D., \& Yunker, E. (1985). Discovering psychology [Computer program]. Bayport, NY: Life Science Associates.

LuDwiG, T. E. (1986). PsychSim [Computer program]. New York: Worth.

Queen's University Psychology Department. (1986). Simlabs [Computer program]. Mishawaka, IN: Soft Productions.

SCARR, S., \& VANDER ZANDEN, J. (1987). Understanding psychology (5th ed.). New York: Random House.

Vom Saal, W., Eckerman, D. A., Balsom, P., \& McDaniel, C. (1984). Getting started with microcomputers in undergraduate education: Hints and guidelines. Behavior Research Methods, Instruments, \& Computers, 16, 144-146. 